\title{
Limited role of patient input in specialty drug coverage policies
}

\author{
Brittany D'Cruz, MPH; Jennifer S Graff, PharmD; Ari D Panzer, BS; and James D Chambers, PhD, MSc, MPharm
}

\section{What is already known about this subject}

- Health plans' drug coverage policies

- Despite increased consumer engagement and financial contributions towards care, consumers' role in shaping their insurance benefits is unclear. guide their enrollees' access to drugs.

\section{What this study adds}

- Health plans do not commonly solicit patient input when developing specialty drug coverage policies.

- Almost half of surveyed plan decisionmakers reported having never engaged with patients or members when developing coverage policies.

- Reported benefits of soliciting patient input included the value of obtaining a humanistic perspective; reported challenges included resource requirements and the quality of obtained information.

\section{Author affiliations}

Brittany D'Cruz, MPH; Tufts Medical Center, Center for the Evaluation of Value and Risk in Health, Boston, MA. Jennifer S Graff, PharmD; National Pharmaceutical Council. Ari Panzer, BS; James D Chambers, PhD, MSc, MPharm; Tufts Medical Center, Center for the Evaluation of Value and Risk in Health, Boston, MA.

\section{AUTHOR CORRESPONDENCE: \\ James D Chambers, 617.636.8882; \\ jchambers@tuftsmedicalcenter.org}

J Manag Care Spec Pharm. 2021;27(8):1067-76

Copyright $(2021$, Academy of Managed Care Pharmacy. All rights reserved.

\section{ABSTRACT}

BACKGROUND: Despite increased financial contributions towards care, consumers' role in shaping their insurance benefits is unclear.

OBJECTIVE: To examine the role played by patient input when US commercial health plans formulate specialty drug coverage policies, along with the benefits and challenges of considering this input.

METHODS: We employed a parallel, mixedmethods approach. First, we reviewed health plans' policy development processes as reported on their websites. Second, we reviewed a data set of private health plan coverage decisions for specialty drugs and examined whether the evidence cited in policies included patient-reported outcomes (eg, health-related quality of life endpoints) and patient-based methodological designs (eg, interviews or surveys of patients). Third, we performed a survey ( $\mathrm{N}=21$ respondents) and interviews ( $\mathrm{N}=5$ interviewees) with plan decision-makers to determine the current role of patient input in plan decision-making, and the benefits and challenges of incorporating this data when formulating specialty drug coverage policies.

RESULTS: We found that plans do not commonly solicit patient input when developing coverage policies, with only two instances of limited interaction between plans and patients or members. 1,316 (9\%) of the studies plans cited in their specialty drug coverage policies included at least one patient-reported endpoint, and $0.4 \%(\mathrm{~N}=62)$ used a patient-based methodological design. Of studies with patient-based designs, 40 used interviews, 26 included surveys/ questionnaires, and one concerned shared decision-making (design categories not mutually exclusive). Almost half of the survey respondents reported having never engaged with patients or members when developing coverage policies. Among respondents who had engaged with patients or members, most reported doing so only rarely. The survey and interviews highlighted various benefits of soliciting patient input, including the value of obtaining a humanistic perspective, and several challenges, including resource requirements and the quality of obtained information.

CONCLUSIONS: We found a notable lack of patient and member engagement by commercial health plans when formulating drug coverage policies. Survey respondents and interviewees identified benefits of accounting for patients' and plan members' values and preferences in specialty drug coverage policies, but also reported a number of important challenges to doing so. 
Consumers are responsible for an increasing share of their health care premiums. ${ }^{1}$ For patients covered under employer-sponsored health plans, cost-sharing requirements have also increased. ${ }^{1}$ Patients are also being asked to be more active participants in their health care, and encouraged to use price transparency tools to "shop around" for their care. ${ }^{2-4}$ Despite increased consumer engagement and financial contributions towards care, consumers' role in shaping their insurance benefits is unclear.

A growing consensus calls for health care to be "patient-centered." The Institute of Medicine (IOM) defines patient-centered care as, "respectful of, and responsive to, individual patient preferences, needs and values, and ensuring that patient values guide all clinical decisions." ${ }^{5}$ Patient involvement is increasingly visible across the health care spectrum. At the research level, the Patient-Centered Outcomes Research Institute has incorporated patient engagement in the selection, conduct and dissemination of patient-centered comparative effectiveness research. ${ }^{6}$ At the regulatory level, the US Food and Drug Administration (FDA) has taken steps to create guidance for incorporating patient-lived experiences into product development. ${ }^{7}$ At the patient-provider level, the IOM and the US Preventive Services Task Force have advocated shared decision-making techniques to better incorporate patient preferences into their care decisions. ${ }^{8,9}$

It is unclear whether health care payers in the United States have embraced "patient-centeredness" as much as other health care system actors. The Centers for Medicare and Medicaid Services (CMS) incorporates a public comment period into its National Coverage Analyses for medical technology and have recently implemented a similar approach for Local Coverage Determinations issued by regional Medicare Administrative Contractors. ${ }^{10,11}$ But the opportunity to be reactive is not typically considered a patient-centered approach. ${ }^{12}$ If we wish to achieve a health system that is patient-centered, it follows that meaningful engagement with patients or consumers in coverage decision-making is valuable. However, the role that patients/ consumers play in medical-technology coverage decisions issued by commercial health plans is poorly understood.

We examined the role played by patient input when US commercial health plans formulate specialty drug coverage policies, along with the benefits and challenges of considering this input. Specifically, we explored what input plans consider, whose input they seek, when plans solicit information, and how they incorporate experiences from patients/members into plan decision-making.

\section{Methods}

We employed a parallel, mixed-methods approach, which incorporated the following components: (1) a review of plan coverage policy development processes; (2) a review of the evidence plans cite in their specialty drug coverage policies; (3) a survey of plan decision-makers; and (4) in-depth interviews with health plan decision-makers.

\section{REVIEW OF HEALTH PLAN COVERAGE DEVELOPMENT PROCESSES}

We searched the websites of health plans included in the Specialty Drug Evidence and Coverage (SPEC) Database to identify their coverage policy development procedures. These plans represent 17 of the largest 20 commercial health plans in terms of premiums collected (see Supplementary Figure 1). SPEC Database details appear elsewhere. ${ }^{13}$ We conducted the searches in February 2019, reviewing each plan's procedures to determine if the plan considered patient or plan member input when developing coverage policies.

\section{REVIEW OF STUDIES CITED IN HEALTH PLAN COVERAGE POLICIES}

We evaluated how often health plans cited studies that included patient-reported outcomes (eg, health-related quality of life endpoints) and patient-based methodological designs (eg, interviews or surveys of patients). We used the SPEC Database to identify Pubmed-indexed studies cited in coverage policies (coverage policies were active December 2018) for 203 specialty drugs. The FDA approved the drugs included in SPEC between the years 1986 and 2018. An automated scan then identified sources with titles or abstracts containing any patient-reported outcome terms or patientbased methodology terms from a predefined list (see Supplementary Table 1). We then manually reviewed titles and abstracts found to contain these terms to confirm that the term appeared in a relevant context, eg, that the term "health-related quality of life" was used in the context of a study endpoint. We determined if each study included a patient-reported endpoint, used a patient-based methodological design, or neither.

\section{SURVEY OF HEALTH PLAN DECISION MAKERS}

We recruited health plan officials involved in drug coverage policy decision-making at US commercial health plans from the RTI Health Solutions advisory panel to participate in an online survey (conducted from December 2018 through February 2019 using Qualtrics software). The survey defined key terms (see Supplementary Table 2), and asked twenty questions about the respondent's health plan, including: (1) whether it considered input from patients and 


\section{TABLE 1 Characteristics of Survey Participants}

\begin{tabular}{|c|c|c|}
\hline & & (\%) \\
\hline \multicolumn{3}{|l|}{ Title/role of participant } \\
\hline Pharmacy director & 14 & $(67)$ \\
\hline Medical director & 6 & $(29)$ \\
\hline Other ${ }^{\mathrm{a}}$ & 1 & (5) \\
\hline \multicolumn{3}{|l|}{ Responsibilities $^{b}$} \\
\hline Making decisions or recommendations regarding medical coverage policies & 20 & $(95)$ \\
\hline Reviewing evidence of treatments during medical policy development & 19 & $(90)$ \\
\hline Selecting treatments to issue medical coverage policies & 18 & $(86)$ \\
\hline Reviewing medical coverage policy appeals & 10 & $(48)$ \\
\hline \multicolumn{3}{|l|}{ Geographic region of health plan ${ }^{b}$} \\
\hline Northeast & 12 & $(57)$ \\
\hline Midwest & 12 & $(57)$ \\
\hline South & 12 & (57) \\
\hline West & 13 & $(62)$ \\
\hline \multicolumn{3}{|l|}{ Business lines } \\
\hline Commercial & 21 & (100) \\
\hline Medicare advantage & 14 & $(67)$ \\
\hline Health insurance exchange & 12 & $(57)$ \\
\hline Medicaid & 11 & $(52)$ \\
\hline Medicare Part D & 9 & $(43)$ \\
\hline \multicolumn{3}{|l|}{ Approximate number of lives covered by health plans } \\
\hline$\leq 1,000,000$ & 4 & $(19)$ \\
\hline$>1,000,0000-2,500,000$ & 4 & $(19)$ \\
\hline$>2,500,000-5,500,0000$ & 5 & $(24)$ \\
\hline$\geq 10,000,000-25,000,000$ & 3 & $(14)$ \\
\hline$>25,000,000-50,000,000$ & 5 & $(24)$ \\
\hline \multicolumn{3}{|l|}{ 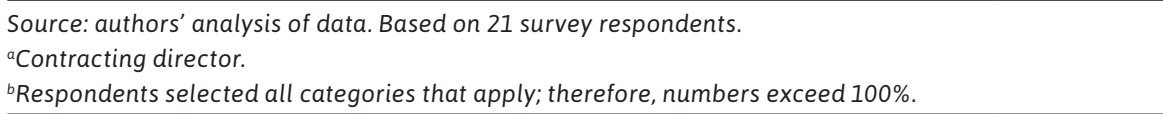 } \\
\hline
\end{tabular}

plan members, (2) whose input it considered, (3) what types of information it considered, (4) when in the coverage decision-making process input from patients and plan members was solicited and received, and (5) how it incorporated the information into decision-making.

\section{KEY-INFORMANT INTERVIEWS}

We recruited a convenience sample of five current or former medical and pharmacy directors directly involved in specialty drug coverage policy development, interviewing them for 30 minutes by phone using a semistructured guide between December 2018 and February 2019. We explored the challenges respondents faced engaging patients and plan members in coverage policy development, the opportunities and benefits of doing so, and potential approaches for incorporating patient views in decision-making. We audio-recorded the interviews and analyzed them qualitatively.

We obtained institutional review board approval for this study. We report descriptive statistics for each research component. Analyses were performed using Stata. ${ }^{14}$

\section{Results}

Table 1 summarizes the characteristics of our 21 survey respondents. We identified coverage-development process documentation for each of the 17 included health plans, and across these, we identified 14,487 studies cited in coverage policies.

\section{WHAT INPUT DO PLANS CONSIDER?}

No health plan reported soliciting patient or member input in their coverage policy development procedures. We found two instances of limited interaction between plans and patients or members. One plan permitted patients and members to observe coverage policy development committee meetings. Another allowed members to e-mail comments to an "E-Review Team."

1,316 (9\%) studies cited in their specialty drug coverage policies included at least one patient-reported endpoint, and $0.4 \%(\mathrm{~N}=62)$ used a patient-based methodological design (see Supplementary Table 1). Of studies with patient-based designs, 40 used interviews, 26 included surveys/ questionnaires, and one shared decision-making (design categories not mutually exclusive).

Nine of the 21 survey respondents (43\%) indicated that they have not undertaken any efforts to engage patients or members when developing specialty drug coverage policies. In contrast, 12 (57\%) reported that they had (rarely, sometimes, or often) solicited input from patients or members 


\section{TABLE 2 Survey Findings for Questions Pertaining to Current Health Plan Engagement Efforts, Rationale, and Future Use}

\begin{tabular}{|c|c|c|}
\hline & $\begin{array}{l}\text { All Respondents } \\
\begin{array}{c}(\mathbf{N}=21) \\
\mathbf{N}(\%)\end{array}\end{array}$ & $\begin{array}{c}\text { Subset who have ever } \\
\text { engaged with patients } \\
(\mathbf{N}=12) \\
\mathbf{N}(\%)\end{array}$ \\
\hline \multicolumn{3}{|c|}{ How often does your health plan undertake patient engagement efforts when developing medical coverage policies? } \\
\hline Never $(0 \%$ of the time) & $9(43)$ & \\
\hline Rarely $(<25 \%$ of the time) & $7 \quad(33)$ & \\
\hline Sometimes ( $25-75 \%$ of the time) & $4 \quad(19)$ & \\
\hline Often ( $>75 \%$ of the time) & $1 \quad(5)$ & \\
\hline Always ( $100 \%$ of the time) & 0 & \\
\hline \multicolumn{3}{|c|}{ What is the likelihood that input from or engagement with patients will increase at your organization in the future? } \\
\hline Not probable & $8(38)$ & \\
\hline Somewhat improbable & $7 \quad(33)$ & \\
\hline Somewhat probable & $5 \quad(24)$ & \\
\hline Very probable & $1 \quad(5)$ & \\
\hline \multicolumn{3}{|l|}{ What is the level of patient input or engagement for medical coverage policies?a } \\
\hline Inform decisions & & $10(83)$ \\
\hline Consult & & $7 \quad(58)$ \\
\hline Participate in a decision & & $2(17)$ \\
\hline As co-decision-maker & & $1 \quad(8)$ \\
\hline As sole decision-maker & & 0 \\
\hline \multicolumn{3}{|l|}{ To what extent does input from patients influence the medical coverage policy decision? } \\
\hline Not at all (0\%) & & $5 \quad(42)$ \\
\hline Slightly (>25\%) & & $5 \quad(42)$ \\
\hline Somewhat (25-75\%) & & $2(17)$ \\
\hline Very influential (>75\%) & & 0 \\
\hline Extremely influential (100\%) & & 0 \\
\hline \multicolumn{3}{|c|}{ What does your health plan hope to achieve by engaging with or eliciting input from patients?a } \\
\hline Inform policy and procedures around medical policy development & & $7 \quad(58)$ \\
\hline Inform plan members of decisions and their rationale & & $7 \quad(58)$ \\
\hline Inform specific coverage policy decisions & & $4 \quad(33)$ \\
\hline $\begin{array}{l}\text { Other: "Obtain general information about the prices, ways improving, physician } \\
\text { engagement and support" }\end{array}$ & & $1 \quad(8)$ \\
\hline
\end{tabular}

engagement and support"

Source: Authors' analysis of data. Based on 21 survey respondents.

aRespondents selected all categories that apply; therefore, numbers exceed $100 \%$.

(Table 2). Ten of the 12 (83\%) survey respondents that had previously engaged with patients or members reported considering published patient-reported outcomes or health-related quality of life endpoints in decision-making, and eight (67\%) reported receiving information directly from plan members or through the customer service channels (Table 3).
All interviewees reported receiving patient and member input from satisfaction surveys or internet-based surveys, and two reported considering patient-reported outcomes in decision-making. Interviewees all said that patient insight regarding their experiences living with a disease, and the barriers patients face, is valuable. One interviewee 


\section{TABLE 3 Survey Findings for Questions Pertaining to Patient Engagement Activities}

\begin{tabular}{|c|c|c|c|c|}
\hline & $\begin{array}{c}\text { Previously } \\
\text { used } \\
\text { n (\%) }\end{array}$ & $\begin{array}{c}\text { Not used yet, } \\
\text { plans to use } \\
\text { n (\%) }\end{array}$ & $\begin{array}{l}\text { No plans } \\
\text { to use } \\
\text { n (\%) }\end{array}$ & $\begin{array}{l}\text { Don't } \\
\text { know } \\
\text { n (\%) }\end{array}$ \\
\hline \multicolumn{5}{|l|}{ Method(s) of patient/member engagement } \\
\hline Published patient-reported outcomes or quality of life endpoints & $10(48)$ & $3(14)$ & $6(29)$ & $2(11)$ \\
\hline Member information/consumer service & $8(38)$ & $3(14)$ & $10(48)$ & 0 \\
\hline Member surveys & $6(29)$ & $2(10)$ & $12(57)$ & $1 \quad(5)$ \\
\hline Consumer/patient engagement officer & $6(29)$ & $1 \quad(5)$ & $13(62)$ & $1 \quad(5)$ \\
\hline Focus groups & $6(29)$ & 0 & $15(71)$ & 0 \\
\hline Consultation document & $6(29)$ & 0 & $13(62)$ & $2(10)$ \\
\hline Surveys of patients with particular condition & $5(24)$ & $3(14)$ & $13(62)$ & 0 \\
\hline Interviews & $4(19)$ & $1 \quad(5)$ & $16(76)$ & 0 \\
\hline Standing patient advisory council & $4(19)$ & $2(10)$ & $15(71)$ & 0 \\
\hline Public hearing or meeting & $3(14)$ & $1 \quad(5)$ & $16(76)$ & $1 \quad(5)$ \\
\hline Other: Patient input from ICER public meetings and reports & $1 \quad(5)$ & 0 & 0 & 0 \\
\hline \multicolumn{5}{|l|}{ Groups/individuals used to elicit input } \\
\hline Organized patient groups (eg, patient advocacy groups) & $7(33)$ & $2(10)$ & $12(57)$ & 0 \\
\hline General plan members (with or without the condition) & $6(29)$ & $2(10)$ & $13(62)$ & 0 \\
\hline Individual patients with the condition that the medication would treat & $5(24)$ & $2(10)$ & $13(62)$ & $1 \quad(5)$ \\
\hline Caregivers & $3(14)$ & $2(10)$ & $15(71)$ & $1 \quad(5)$ \\
\hline \multicolumn{5}{|c|}{ Type of information collected from patients to be considered during medical coverage policy decision-making } \\
\hline How well do currently available medications/therapies help manage the condition & $11(52)$ & $2(10)$ & $8(38)$ & 0 \\
\hline Potential disadvantages of the medication compared to current treatments & $9(43)$ & $3(14)$ & $8(38)$ & $1 \quad(5)$ \\
\hline How would the medicine impact (or improve) patient quality of life & $7(33)$ & $3(14)$ & $11(52)$ & 0 \\
\hline How does the condition affect day-to-day life & $6(29)$ & $3(14)$ & $12(57)$ & 0 \\
\hline Medication's potential impact on patients' family/caregivers & $6(29)$ & $3(14)$ & $12(57)$ & 0 \\
\hline How the condition affects productivity or absenteeism from work & $5(24)$ & $3(14)$ & $13(62)$ & 0 \\
\hline
\end{tabular}

indicated that they consider patient-engagement summaries and public comment from the Institute for Clinical and Economic Review reports to be a useful source of patient input information.

\section{WHOSE INPUT DO PLANS SEEK?}

Nine survey respondents (43\%) indicated that they had engaged with at least one type of patient group or an individual when developing specialty drug coverage policies. Among the nine respondents who had engaged with a patient group or individual, seven engaged with organized patient groups (78\%), six with general health plan members (67\%), five with individual patients (56\%), and three with caregivers (33\%; categories not mutually exclusive).
Survey respondents stated it was most important to engage with patients with chronic diseases $(\mathrm{N}=9 ; 45 \%)$, rare diseases $(\mathrm{N}=8 ; 40 \%)$, and pediatric conditions $(\mathrm{N}=8$; $40 \%$ ) when developing coverage policies for treatments indicated for these conditions (see Supplementary Table 3). The interviewees suggested that health plans would benefit from engaging with patients and members with knowledge of medicine and of how the healthcare system works. One interviewee suggested that it would be beneficial to include plan members-and not just patients with a particular condition-in the coverage policy development process.

\section{WHEN DO PLANS SOLICIT INPUT?}

Survey respondents stated that they most often engaged with patients and members when developing coverage 


\section{FIGURE 1 Survey Findings for Questions Pertaining to Suggested Benefits and Challenges Associated With Patient Input In Specialty Drug Coverage Policies}

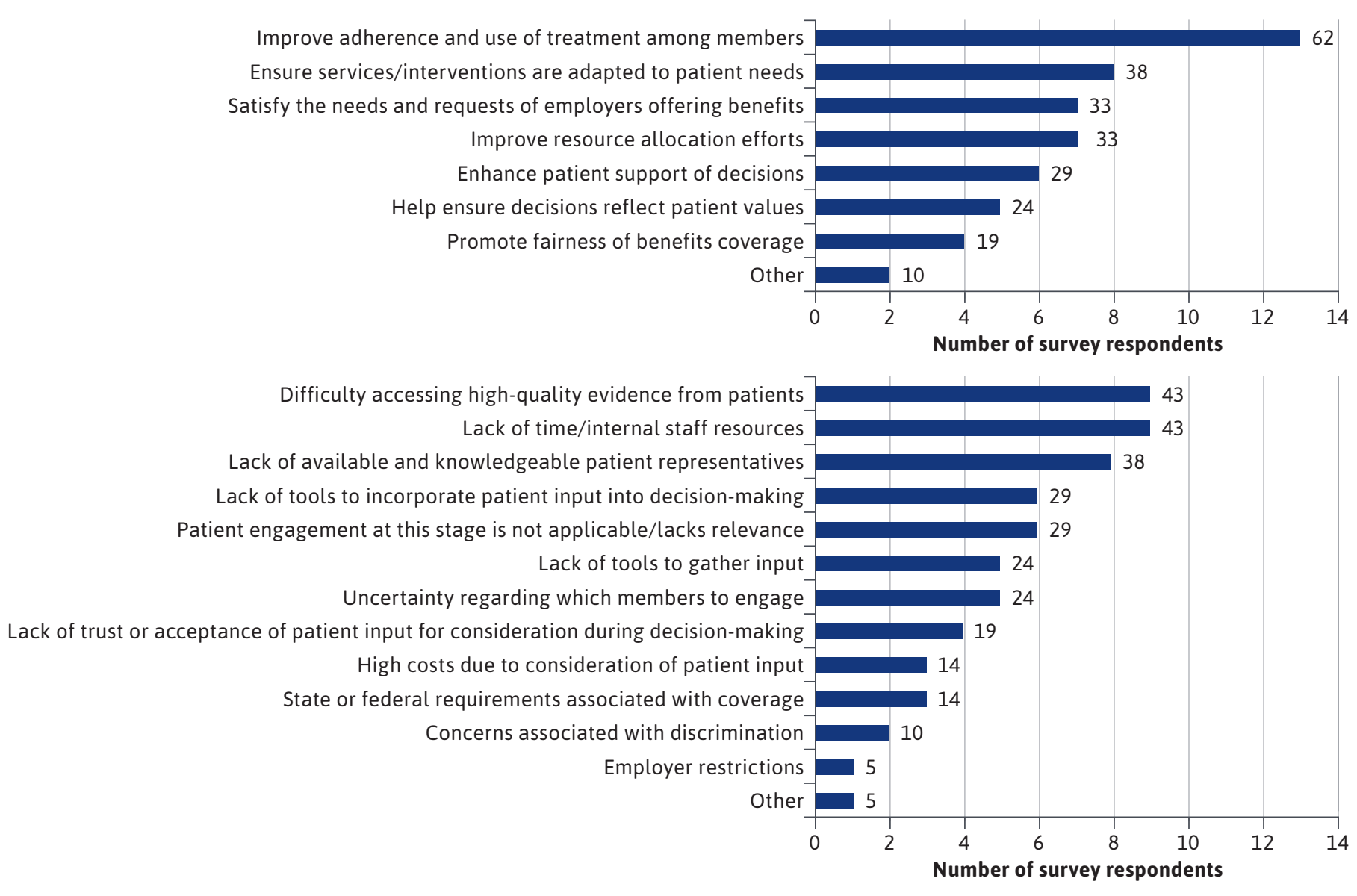

Source: Authors' analysis of data. Based on 21 survey respondents.

policies, and less often when selecting interventions for review, conducting coverage deliberations, or during appeals (see Supplementary Table 4). Interviewees stated that the earlier plans elicit patient and member input during the coverage policy development process, the better.

\section{HOW DO PLANS INCORPORATE INPUT INTO DECISION-MAKING?}

Of the 12 survey respondents who had previously engaged with patients or members, most reported doing so to inform policy and procedures regarding coverage policy development ( $N=7$; 58\%; Table 2). Survey respondents indicated that the most common types of patient or member information considered pertained to the sufficiency of available medications or therapies to manage a condition and the potential disadvantages of the medication compared to current treatments (Table 3). Similarly, seven (58\%) of the survey respondents engaged with patients and members to inform plan members of decisions and their corresponding rationale.

Overall, survey respondents and interviewees rarely regarded patient and member input to be influential. Of the 12 survey respondents who had previously engaged with patients or members, 10 (83\%) said that the input influenced coverage policy development "not at all" or "slightly," and two (17\%) indicated that it was "somewhat influential" (Table 2). These findings are consistent with feedback from interviewees, who also said that patient/member input has a limited influence on plan decision-making. 
Among the survey respondents, $71 \%$ said that it was "not probable" or "somewhat improbable" that the influence of patient and member input would increase in the future. However, the interviewee opinions on the matter varied. Some considered it unlikely that patient and member engagement would become more commonplace, while others expected that patients and members would have a growing role in coverage policy development. One interviewee said that their health plan was currently undertaking efforts to incorporate patient input across all aspects of the plan, including coverage policy development.

\section{THE BENEFITS AND CHALLENGES OF INCORPORATING PATIENT AND MEMBER INPUT}

Survey respondents said that engaging patients/members during coverage policy development improved patient adherence to treatment $(\mathrm{N}=13 ; 62 \%)$, tailored covered servicestoplanmemberneeds $(\mathrm{N}=10738 ; 38 \%)$, satisfied theneeds and requests of employers offering benefits $(\mathrm{N}=7 ; 33 \%)$, and improved resource allocation ( $N=7 ; 33 \%$; Figure 1$)$.

Interviewees agreed that the greatest benefit of engaging patients and members was it provided a humanistic perspective not otherwise available from the clinical data. Another common theme among interviewees was that patients and members could provide valuable insight into the relative importance of different study endpoints.

Survey respondents stated that the most frequent challenges plans encounter in gathering patient input are ensuring the quality of the evidence $(\mathrm{N}=9 ; 43 \%)$; insufficient time and staff to effectively elicit patient input $(\mathrm{N}=9$; $43 \%)$; and an inadequate number of knowledgeable patient representatives ( $\mathrm{N}=8 ; 38 \%$; Figure 1).

Interviewees conveyed similar themes. For example, they highlighted the difficulty of convincing other health plan officials of the relevance of patient and member input to coverage policy development. Some interviewees said that not having a suitable framework for combining data from patients and members with clinical trial data hindered the incorporation of patient input into decision-making. The interviewees also highlighted time and resource constraints and said that processes required to elicit input from patients and members could increase costs. There was also concern that a lack of knowledgeable or engaged patients and members who understand the healthcare system may diminish the quality of the information received. Finally, interviewees expressed concern regarding the "neutrality" of input received from patient advocacy groups funded by pharmaceutical companies.

\section{Discussion}

We found a notable lack of patient and member engagement by commercial health plans when formulating drug coverage policies. None of the health plans we studied reported having a formal process for including patient/member input into coverage policy development, and only a small proportion of the evidence cited in coverage policies included patient-reported outcomes or used a patient-based design. Almost half of the survey respondents reported having never engaged with patients or members when developing coverage policies. Among respondents who had engaged with patients or members, most reported doing so only rarely. While the survey respondents and interviewees recognized the benefits of engaging patients and members, they also highlighted challenges.

First, there was a lack of consensus regarding the appropriate role of patient input in decision-making. For example, one plan official we interviewed explained that, "Our job as a health plan is to apply the benefits contracted by [the] employer or payer. Patient satisfaction/requests etc. are just not relevant to that task." In contrast, other survey respondents and interviewees recognized the value of patient and member input, with one interviewee stating, "Clinical evidence basically paints a black and white picture. Patients and physicians paint the colors in that picture... and tell me whether what we're doing has value."

Second, information from patients and members may suffer from quality problems because few patients and members have detailed medical knowledge about their condition and how the health care system works.

Third, meaningfully engaging with patients and members would be resource-intensive.

Finally, there is no suitable framework to integrate patients and member data with the epidemiologic, clinical, and economic data currently used in coverage decision formulations. Research can help address these challenges.

Several efforts are ongoing to develop and improve patient-reported outcomes in clinical studies and to ensure performance measures are meaningful to patients. ${ }^{15-17}$ Some efforts facilitate the sharing of information regarding patient experiences, needs, and insights; others educate patient representatives engaging in value and coverage discussions. ${ }^{18,19}$ Future research should examine how patient and member input can improve decision-making, identify optimal approaches for engaging patients, and explore methods such as multi-criteria decision analysis or other deliberative methods, to incorporate qualitative and quantitative patient-reported outcomes and values into existing decision-making processes. 
US commercial health plans compare unfavorably to their counterparts elsewhere. Outside the United States, many health technology assessment (HTA) organizations routinely engage with patients as part of technology assessments, although approaches differ across organizations. ${ }^{20-23}$ Health technology assessment agencies based in various countries, including Australia, Canada, Germany, and the United Kingdom encourage submissions from patient groups and consortiums. ${ }^{12,22,24}$ In the United Kingdom, the National Institute for Health and Care Excellence (NICE) has also implemented a Public Involvement Program, which supports patient organizations as they provide feedback on technology guidance development. ${ }^{25}$ Many countries also include patients or the public on advisory committees (eg, NICE's Citizen Council) or as members of existing committees (eg, Pan-Canadian Oncology Drug Review). ${ }^{26,27}$ It is notable that health care systems in Australia, Canada, Germany, and the United Kingdom are more centralized than the US health care system. It may be that the fragmented nature of US health care has been a contributing factor to the relative lack of patient involvement in decision-making.

\section{LIMITATIONS}

Our study has these limitations. First, we did not fully account for the benefits and challenges associated with obtaining input from different categories of respondents (eg, health plan members vs patients). Second, the opinions of the survey respondents and interviewees may differ from those of other executives or medical directors at those same plans. Third, we did not use the same set of plans across all components of this research. Fourth, our findings may not be generalizable to other commercial plans or public health plans. Fifth, we did not review drugs' registration studies, which are reported in the drugs' FDA labels, to determine if they included patient-reported outcomes.

\section{LOOKING FORWARD}

Despite the impression among survey respondents and interviewees that plans will not further incorporate patient and member input into coverage policy development, there are positive signs. For instance, patient input can benefit regulatory decisions, value determination, treatment guidelines, and reimbursement decisions. ${ }^{7,9,28,29}$

Among public health care payers, there is a growing emphasis on utilizing input from patients to measure quality, incentivize choice, and determine coverage. For instance, CMS now includes patient-centered value measures when assessing population health. CMS has also given patients more voice in the measurement of quality. ${ }^{30}$ Finally, CMS has set a goal of increasing the consideration of the patient experience when measuring plan quality and has given Medicare Part D and Medicare Advantage plans the authority to include beneficiaries on Pharmacy and Therapeutics committees. ${ }^{31,32}$

The Institute of Clinical and Economic Review (ICER), a US-based independent group that evaluates the clinical and economic value of medical innovations, has a patient engagement program that incorporates the views of patient organizations and individual patients into its assessments. Notably, one interviewee reported that their health plan used published ICER reports as a source of patient-related information when formulating their coverage policies.

Commercial health plans can make their specialty drug coverage policies more patient-centered. As a starting point, the plans could take the lead from HTA agencies that have themselves incorporated patient engagement into their assessment processes..$^{22,33}$ For example, in our review of health plan coverage policy development processes we found that 13 of 17 plans seek physician input either from community physicians practicing in the relevant clinical areas or specialty medical associations. We also found that plans permitted clinicians to attend and observe or participate in policy meetings. In contrast, input from patient groups related to the lived experience was not solicited as part of the plan processes we reviewed and only one plan allowed patients to observe committee meetings. Another approach is to incentivize plans to engage with patients. This could originate from the public health programs, employer groups and other large purchasers of health care. Alternatively, health plan accreditation bodies, such as the National Committee for Quality Assurance, could require patient engagement as an accreditation criterion. Whatever the trigger, health plans' starting point should reflect FDA's three key elements to increase patient engagement: cultural change, communication, and regulatory guardrails. ${ }^{34}$

Various US health care stakeholders are becoming increasingly patient-centered and US commercial health plans must also find a way to catch up.

\section{Conclusions}

Health plans do not commonly solicit input from patients or plan members when developing specialty drug coverage policies. Surveyed and interviewed health plan officials involved in coverage policy development recognized various benefits of soliciting input from patients and members, but they also highlighted several challenges. If plans are to become more patient-centered, they must first address challenges to ensure that their specialty drug coverage policies reflect patient and plan member values and preferences. 


\section{DISCLOSURES}

National Pharmaceutical Council provided funding for this research.

\section{REFERENCES}

1. Kaiser Family Foundation. Employer Health Benefits 2019 Annual Survey. Published September 25, 2019. Accessed November 9, 2020. http://files.kff.org/ attachment/Report-Employer-HealthBenefits-Annual-Survey-2019

2. Executive Order on Improving Price and Quality Transparency in American Healthcare to Put Patients First. June 24, 2019. 84 FR 30849-52. Accessed November 9, 2020. https://www.federalregister.gov/ documents/2019/06/27/2019-13945/ improving-price-and-quality-transparency-in-american-healthcare-to-putpatients-first

3. Internal Revenue Service, Employee Benefits Securite Administration, Centers for Medicare \& Medicaid Services. Transparency in Coverage Proposed Rule CMS-9915-P. 84 FR 65464-65523. Accessed November 9, 2020. https://www.federalregister.gov/ documents/2019/11/27/2019-25011/ transparency-in-coverage

4. Higgins A, Brainard N, Veselovskiy G. Characterizing health plan price estimator tools: findings from a national survey. Am J Manag Care. 2016;22(2):126-31.

5. Institute of Medicine (US) Committee on Quality of Health Care in America. Crossing the quality chasm: a new health system for the 21st century. Washington (DC): National Academy Press (US); 2001.

6. Patient-Centered Outcomes Research Institute. Our story. Accessed November 9, 2020. https://www.pcori.org/ about-us/our-story

7. Hunter NL, O'Callaghan KM. Califf RM. Engaging patients across the spectrum of medical product development: view from the US Food and Drug Administration. JAMA. 2015;314(23):2499-500.

8. Berwick, DM. A user's manual for the IOM's 'Quality Chasm' Report. Health Aff (Millwood). 2002;21(3):80-90.
9. Sheridan S.L, Harris RP, Woolf SH. Shared decision making about screening and chemoprevention: a suggested approach form the US Preventive Services Task Force. Am J Prev Med. 2004;26(1):56-66.

10. Centers for Medicare \& Medicaid Services. National coverage analyses (NCAs) open for public comment. Alphabetical Index. Accessed November 9, 2020. https://www.cms.gov/medicare-coverage-database/indexes/ nca-open-for-public-comment-index.aspx

11. Health, S. CMS Revises Medicare Program Manual to Boost Patient Access to Care. Accessed November 9, 2020. https://patientengagementhit.com/ news/cms-revises-medicare-programmanual-to-boost-patient-access-to-care

12. National Health Council. The National Health Council Rubric to capture the patient voice: A guide to incorporating the patient voice into the health ecosystem. Accessed November 9, 2020. https://nationalhealthcouncil.org/ patient-engagement-rubric/

13. Chambers JD, Kim DD, Pope EF, Graff JS, Wilkinson CL, Neumann PJ. Specialty drug coverage varies across commercial health plans in the US. Health Aff (Millwood). 2018;37(7):1041-47.

14. StataCorp. 2015. Stata Statistical Software: Release 14. College Station, TX: StataCorp LP.

15. Calvert M, Kyte D, Mercieca-Bebber R, et al. Guidelines for inclusion of patientreported outcomes in clinical trial protocols: the SPIRIT-PRO Extension. JAMA. 2018;319(5):483-94.

16. AMCP partnership forum: improving quality, value, and outcomes with patientreported outcomes. J Manag Care Spec Pharm. 2018;24(3):304-310.

17. Centers for Medicare \& Medicaid Services. Meaningful Measures Hub. Accessed November 9, 2020. https://www.cms.gov/Medicare/ Quality-Initiatives-Patient-AssessmentInstruments/QualityInitiativesGenInfo/ MMF/General-info-Sub-Page
18. National Health Council: Value framework get-ready checklist for patient organizations. September 2016. Accessed November 9, 2020. https:// nationalhealthcouncil.org/wp-content/ uploads/2019/12/Get_Ready_Checklist. pdf

19. FasterCures. Patient Insight Navigator. Accessed November 9, 2020. https://milkeninstitute.org/article/ fastercures-2019-review

20. Whitty JA. An international survey of the public engagement practices of health technology assessment organizations. Value Health. 2013;16(1):155-63.

21. Weeks L, Polisena J, Scott, AM, Holtorf A-P, Staniszewska S, Facey K. Evaluation of patient and public involvement initiatives in health technology assessment: a survey of international agencies. Int J Technol Assess Health Care. 2017;33(6):715-23

22. Facey KM, Hansen HP, Single ANV. Patient Involvement in Health Technology Assessment. 1st ed. Adis, Singapore; 2017.

23. Kristensen FB, Husereau D, Huić M, et al. Identifying the need for good practices in health technology assessment: summary of the ISPOR HTA Council working group report on good practices in HTA. Value Health. 2019;22(1):13-20.

24. CADTH. (n.d.) Patient Input and Feedback. Accessed June 30, 2021. https://www.cadth.ca/patientinput-and-feedback

25. National Institute for Health and Care Excellence. Patient and public involvement policy. Accessed November 9, 2020. https://www.nice. org.uk/about/nice-communities/niceand-the-public/public-involvement/ public-involvement-programme/ patient-public-involvement-policy

26. National Institute for Health and Care Excellence. Guide to the methods of technology appraisal 2013. Published April 4, 2013. Accessed November 9, 2020. https://www.nice. org.uk/process/pmg9/resources/ guide-to-the-methods-of-technologyappraisal-2013-pdf-2007975843781 
27. Canadian Agency for Drugs and Technologies in Health. The pCODR Expert Review Committee (pERC). Accessed June 30, 2021. https:// www.cadth.ca/collaborationand-outreach/advisory-bodies/ pcodr-expert-review-committee-perc

28. FasterCures, Avalere. PatientPerspective Value Framework (PPVF) Version 1.0 May 2017. Accessed June 30, 2021. https://www.fastercures.org/ assets/Uploads/PPVF-Version-1.0Methodology-Report-Final.pdf

29. Institute for Clinical and Economic Review. 2020-2023 value assessment framework. January 31, 2020. Accessed November 9, 2020. https:// icer.org/wp-content/uploads/2020/10/ ICER_2020_2023_VAF_102220.pdf
30. Centers for Medicare \& Medicaid Services. CY 2020 revisions to payment policies under the physician fee schedule and other changes to part B payment policies final rule. Accessed November 9 2020. https://s3.amazonaws. com/public-inspection.federalregister. gov/2019-24086.pdf

31. Centers for Medicare \& Medicaid Services. Contract Year 2021 and 2022 Medicare Advantage and Part D Proposed Rule (CMS-4190-P). 85 FR 9002. Accessed November 9, 2020. https://www.federalregister.gov/ documents/2020/02/18/2020-02085/ medicare-and-medicaid-programscontract-year-2021-and-2022-policy-andtechnical-changes-to-the
32. Centers for Medicare \& Medicaid Services. Modernizing part D and Medicare Advantage to lower drug prices and reduce out-of-pocket expense (CMS4180-F). Accessed November 9, 2020. https://www.govinfo.gov/content/pkg/ FR-2019-05-23/pdf/2019-10521.pdf

33. Gauvin F-P, Abelson J, Giacomini M, Eyles J, Lavis JN. "It all depends": conceptualizing public involvement in the context of health technology assessment agencies. Soc Sci Med. 2010;70(10):1518-26

34. National Health Council. Dialogue/ advancing meaningful patient engagement in research, development, and review of drugs. Published September 22, 2015. Accessed November 9, 2020. https:// nationalhealthcouncil.org/wp-content/ uploads/2019/12/PatientEngagementWhitePaper.pdf 